\title{
Avaliação Microbiológica e Físico-Química de Queijos Probióticos Contendo Bifidobacterium longum
}

Luana Sabrine Silva (I), Ana Cláudia Morais Souza (I), Marcelo Morais Maria (I), Cláudia Freire de Andrade Morais Penna (II), Washington Azevedo da Silva (I), Christiano Vieira Pires (I), Marcelo Resende Souza (II), Andréia Marçal da Silva (I)

(I) UFSJ - Universidade Federal de São João del-Rei (Rodovia MG 424, Km 47 - Sete Lagoas MG), (II) UFMG - Universidade Federal de Minas Gerais (Av. Antônio Carlos, 6627 - Pampulha - Belo Horizonte - MG)

\section{Resumo}

Muito se discute sobre alimentos que possuam em sua composição ingredientes e/ou micro-organismos que ofereçam benefícios à saúde, chamados de "alimentos funcionais". Os queijos têm sido uma alternativa para a incorporação de micro-organismos probióticos, pelo fato de permitirem a sobrevivência dos mesmos na matriz alimentar (maior valor de $\mathrm{pH}$, alto teor de gordura e menores teores de oxigênio dissolvido, quando comparados aos leites fermentados). Objetivou-se neste trabalho elaborar um queijo funcional contendo Bifidobacterium longum como cultura probiótica. Foram elaborados queijos com e sem a adição da bactéria probiótica, sendo utilizadas embalagens tradicionais (plásticas) e modificadas (multicamadas, submetidas a vácuo). Análises microbiológicas e físico-químicas foram feitas, em três repetições, com 1, 7, 14, 21 e 28 dias de estocagem sob refrigeração. Quanto aos patógenos e deteriorantes, todas as amostras de queijo submetidas à embalagem modificada apresentaram resultados de acordo com padrões exigidos pela legislação, durante todo o período de armazenamento. Os queijos comuns e probióticos acondicionados em embalagens tradicionais apresentaram altas contagens de bolores e leveduras a partir do $14^{\circ}$ dia. Não houve diferença (PB. longum, independentemente do tipo de embalagem. Os valores

\footnotetext{
Referência:

Luana Sabrine Silva, Ana Cláudia Morais Souza, Marcelo Morais Maria, Cláudia Freire de Andrade Morais Penna, Washington Azevedo da Silva, Christiano Vieira Pires, Marcelo Resende Souza, Andréia Marçal da Silva. Avaliação Microbiológica e Físico-Química de Queijos Probióticos Contendo Bifidobacterium Longum. In: Anais do 12º Congresso Latinoamericano de Microbiologia e Higiene de Alimentos - MICROAL 2014 [= Blucher Food Science Proceedings, num.1, vol.1]. São Paulo: Editora Blucher, 2014. DOI 10.5151/foodsci-microal-157
} 
médios de umidade foram inferiores a 55\% em todos os tratamentos. As maiores médias percentuais para sólidos totais e cinzas foram observadas nos queijos comuns, independentemente do tipo de embalagem. $\mathrm{O}$ teor de proteína mais elevado (16,38\%) foi obtido no queijo comum, com embalagem tradicional. O queijo comum, com embalagem modificada, apresentou o maior teor de gordura $(45,72 \%)$. Os queijos acondicionados em embalagem modificada apresentaram maiores valores de acidez titulável, sendo que o maior valor $\left(5,32^{\circ} \mathrm{D}\right)$ foi verificado no queijo probiótico. Embalagens modificadas foram mais eficazes em relação à vida de prateleira dos queijos, mantendo-os dentro dos padrões de qualidade estabelecidos pela legislação até o final do período de estocagem. Os queijos probióticos mantiveram-se com contagens de B. longum superiores ao exigido pela legislação durante toda a estocagem, conferindo aos produtos alegação de funcionalidade.

Palavras-Chave: alimentos funcionais, Bifidobacterium longum, embalagem modificada, probióticos, queijo tipo Minas frescal

Agência de Fomento: FAPEMIG 